\title{
Correction to: Connecting Knowledge Compilation Classes and Width Parameters
}

Antoine Amarilli ${ }^{1} \cdot$ Florent Capelli $^{2,3} \cdot$ Mikaël Monet $^{1,3} \cdot$ Pierre Senellart $^{1,3,4}$

Published online: 25 January 2020

(C) Springer Science+Business Media, LLC, part of Springer Nature 2020

\section{Correction to: Theory of Computing Systems \\ https://doi.org/10.1007/s00224-019-09930-2}

The article title in the original publication contains an error. The correct title is presented in this Erratum.

The online version of the original article can be found at https://doi.org/10.1007/s00224-019-09930-2

Mikaël Monet

mikael.monet@imfd.cl

Antoine Amarilli

antoine.amarilli@telecom-paristech.fr

Florent Capelli

florent.capelli@univ-lille.fr

Pierre Senellart

pierre.senellart@ens.fr

1 LTCI, Télécom ParisTech, Université Paris-Saclay, Paris, France

2 CRIStAL, Université de Lille, CNRS, Lille, France

3 Inria, Lille, Paris, France

4 DI ENS, ENS, CNRS, PSL University, Paris, France 